\title{
Submicroscopic duplication in Xq28 causes increased expression of the MECP2 gene in a boy with severe mental retardation and features of Rett syndrome
}

\author{
M Meins, J Lehmann, F Gerresheim, J Herchenbach, M Hagedorn, K Hameister, J T Epplen
}

J Med Genet 2005;42:e12 (http://www.jmedgenet.com/cgi/content/full/42/2/e12). doi: 10.1136/jmg.2004.023804

$\mathrm{R}$ ett syndrome is an $\mathrm{X}$ linked mental retardation syndrome almost exclusively affecting girls, and has long been regarded as an $\mathrm{X}$ linked dominant condition lethal in hemizygous males. ${ }^{1}$ Mutations in the gene encoding the methyl-CpG binding protein 2 (MECP2) were demonstrated as the cause of Rett syndrome, ${ }^{2}$ and confirmed by a number of studies. The vast majority (95\%) of MECP2 mutations occurs de novo. Girls affected by "classic" Rett syndrome show mental retardation and regression, with a typical pattern of symptoms including initially normal development, stagnation, loss of acquired abilities, stereotypic hand movements, regression of speech, profound psychomotor retardation, epilepsy, and autism, although molecular diagnostics has proven that variant clinical forms exist. $^{34}$

It has recently been shown that missense mutations in $M E C P 2$ can cause severe neonatal encephalopathy in boys. ${ }^{5}$ Classic Rett phenotypes in boys have so far only been reported in rare cases of somatic mosaicism or XXY karyotypes. $^{6-11}$ In girls, larger intragenic deletions are responsible for about $11-16 \%$ of typical Rett syndrome without point mutations in the coding exons. ${ }^{12}{ }^{13}$ Larger deletions have not yet been found in boys, and duplications of MECP2 have not yet been reported as a cause for typical Rett syndrome at all. We have established quantitative PCR for diagnosis of deletions affecting $M E C P 2$, and in this paper, we report a boy manifesting clinical features of Rett syndrome and a submicroscopic duplication within the cytogenetic band Xq28 encompassing the entire MECP2 gene.

\section{CLINICAL FEATURES}

The boy is the second child of healthy, unrelated parents, whose older brother had developed normally. There is no family history of mental retardation or developmental disorders. The patient was born in the 4lst week after an uneventful pregnancy. Birth was spontaneous but with protracted labour (birth weight $3940 \mathrm{~g}$, length $54 \mathrm{~cm}$, head circumference $36.2 \mathrm{~cm}$ ). Head growth was normal and did not decelerate (head circumference $54.5 \mathrm{~cm}$ at 7.5 years), but growth of length was retarded (length $117 \mathrm{~cm}$ at 7.5 years). Psychomotor development was retarded from birth. Initially, reduced movements, muscular hypotonia, and insufficient weight gain were noticed. The patient could not turn at the age of 15 months, and could not sit up until the age of 4 years. The first stereotypic hand movements were noticed at the age of 4 years. At the age of 6 years, he was crawling and able to walk a few steps with assistance. He was able to hold things and play with toys, but showed gradual loss of purposeful hand use around the same age. There was no spasticity or fixed scoliosis. The patient never learned to speak, but made babbling sounds to communicate basic needs.

\section{Key points}

- Rett syndrome has been recognised as one of the major causes of mental retardation in girls. Both point mutations and deletions affecting the MECP2 gene have been identified in girls with this neurodevelopmental disorder. Only a few boys with MECP2 mutations have been described, most of whom have a severe neonatal encephalopathy.

- We describe a complete duplication of MECP2 due to a submicroscopic duplication of approximately $430 \mathrm{~kb}$ within $X_{q 2} 2$ in a boy with severe mental retardation and features of Rett syndrome. MECP2 is the only gene involved in the duplication that is known to be relevant in mental retardation or essential for neural development, and was found to be completely duplicated.

- The size of the duplication was analysed by quantitative PCR. The proximal border of the duplicated segment was located to a region at least $8.4 \mathrm{~kb} 5^{\prime}$ from the first exon of LICAM. The distal border lies within the FLNA gene, but leaving the functional gene copy intact. We provide evidence that the duplication leads to elevated MECP2 mRNA levels in lymphoblastoid cells.

- The mother of the patient carries the same duplication, but is asymptomatic, which may be attributed to extremely skewed $\mathrm{X}$ inactivation.

- These findings complement the understanding of pathogenesis of Rett syndrome and may have important implications for development of potential gene therapy strategies.

- This is the first report showing that, in a manner equal to gene deletion with loss of MECP2 function, duplication and overexpression of MECP2 can cause mental retardation with features of Rett syndrome.

During the first hospitalisation at the age of 10 months, magnetic resonance imaging (MRI) showed mildly enlarged inner and outer liquor spaces, but no retardation of myelination. In the following years, thorough screening for metabolic disorders including liquor tests revealed normal results. No signs of energy metabolism disorders, organoacidopathies, aminoacidopathies, peroxisomal or lysosomal disorders, or storage disorders were detected. There was no organomegaly. Ophthalmological examination showed mild

Abbreviations: FISH, fluorescence in situ hybridisation; MRI, magnetic resonance imaging; SSCP, single strand conformational polymorphism 
hyperopia, but no retinopathy or optic atrophy. Nerve conduction velocities and electromyogram were normal. Owing to insufficient weight gain, a gluten enteropathy was suspected at the age of 1 year. A gluten free diet has been followed since then, although gliadin antibodies had not been found and enteroscopy had never been carried out to verify the diagnosis. Weight normalised gradually, and was in the normal range at the age of $6 \frac{3 / 4}{4}$ years.

No seizures were noted in the first years. EEG showed signs of unspecific encephalopathy, with theta waves, but no epileptogenic potentials between the age of 3 and 4.5 years. At 6 years, the parents observed phases of absence in the child. Diagnostic evaluation confirmed generalised epilepsy with absences, and myotonic-astatic and tonic seizures. EEG was markedly abnormal, with hypersynchronic activity (spike and sharp slow wave complexes, multifocal but most pronounced in the right hemisphere) and a very slow basal rhythm in the awake EEG. Antiepileptic therapy was induced, but treatment of epilepsy proved to be difficult. Monotherapy with different drugs (topiramate, clobazame, lamotrigine) was unsatisfactory. Current medication with lamotrigine and sulthiame has led to a decrease in seizure frequency, but the patient still has at least one seizure daily.

MRI showed unspecific white matter changes, which may also be secondary and caused by epilepsy, including small cystic structures in the supratentorial white matter surrounding the trigonum (probably enlarged Virchow-Robin spaces). Cortex relief, and size of inner and outer liquor spaces, brain stem, and cerebellum were interpreted as normal.

At the age of $6 \frac{3}{4}$ years, the boy showed severe global retardation and autistic features. The parents described regression of motor abilities over 6 months with loss of crawling and assisted walking, and suggested coincidence with onset of epilepsy. However, motor abilities did not recover significantly after onset of medication. Speech development was still not recognisable. Stereotypic hand movements and teeth grinding were observed. Dysmorphological evaluation showed only mild dysmorphic features such as a narrow midface and undescended testis. The extremities were frequently pink and cold, indicating mild peripheral vasomotor disturbance. The patient is now 8 years old and has increasing problems with swallowing, resulting in salivation and decrease in weight gain. No breathing irregularities have been observed as yet. Further regression of basic communication skills and loss of purposeful hand use and interest in toys has been noted.

\section{MATERIALS AND METHODS \\ Molecular genetic analysis}

Mutation screening in MECP2 was performed by PCR amplification of coding exons in overlapping fragments, followed by single strand conformational polymorphism (SSCP) analysis.

The analysis included all parts of the open reading frame in exons 2-4 of the full length transcript $M E C P 2 A$, and also the part of exon 1 coding in the alternative transcript $M E C P 2 B$ recently reported..$^{14}$ Band shifts indicative of small intragenic aberrations were not detected (not shown).

Quantification of MECP2 gene dosage, characterisation of the duplicated region, and fine mapping of the duplication breakpoints were performed using a quantitative PCR approach with SYBR-Green I detection, and the comparative threshold cycle method. ${ }^{15}{ }^{16}$ Analysis was carried out on the iCycler iQ real time PCR detection system (Bio-Rad, CA, USA) and performed repeatedly for three independent MECP2 amplicons (each three times, in duplicate). Two primer pairs for the fourth exon (primers Rett ex4F1/ex4Rl, and Rett ex4F2/ex4R2) and one for the third (primers Rett ex3F/ ex3R), and reference amplicons in the $A L B$ and PMP22 genes were used (table 1). Size of the duplication was analysed using a primer set for amplicons covering parts of Xq27-q28 (table 1). Genomic sequences were obtained from the UCSC site (http://genome.ucsc.edu/). ${ }^{17}$ Primers were designed with lengths of 18-24 nucleotides, G+C contents 50-65\%, PCR product length $75-150 \mathrm{bp}$. Specificity and exact position (physical distance) of primers were verified using the BLAT interface at the UCSC site. Standard curves and PCR efficiency were run to confirm applicability of the comparative threshold cycle method.

Quantitative PCR reactions contained $0.6 \mu \mathrm{mol} / \mathrm{l}$ each primer and $12.5 \mu \mathrm{l}$ SYBR Green PCR Master Mix (ABgene, $\mathrm{UK}$ ) in a total of $25 \mu \mathrm{l}$. Assays included DNA standards, no template control, or $2.5 \mathrm{ng} / \mu \mathrm{l}$ of the patient DNA in two replicates. Cycling conditions were $50^{\circ} \mathrm{C}$ for 2 minutes, $95^{\circ} \mathrm{C}$ for 15 minutes, and 40 cycles of $95^{\circ} \mathrm{C}$ for 30 seconds, then $62^{\circ} \mathrm{C}$ for 1 minute (data collection step), followed by a melting curve analysis $\left(95^{\circ} \mathrm{C}\right.$ for 1 minute, $55^{\circ} \mathrm{C}$ for $10 \mathrm{sec}-$ onds, temperature increase by $0.5^{\circ} \mathrm{C}$ every 10 seconds (data collection) up to $95^{\circ} \mathrm{C}$ ) to confirm specificity of the PCR reaction.

Quantification of target amplicons was performed relative to reference amplicons with the comparative threshold cycle method. Quantitative data were normalised against the average of two or four female controls (MECP2 amplicons,

Table 1 Primer pairs for amplicons used for quantitative PCR. Position of amplicons in Mb refers to UCSC

\begin{tabular}{|c|c|c|}
\hline Name & Nucleotide sequence & Position \\
\hline \multicolumn{3}{|l|}{ Test amplicons } \\
\hline LICAM intl $\mathrm{F}$ & TCGGGAGGTATITGACCACG & 151608 \\
\hline L1CAM int1 $R$ & AACACCATCACGGTAACACCC & \\
\hline LCA10 intl F & CCTTGAAGCGCTGATTGTCC & 151618 \\
\hline LCA10 intl $R$ & TCCCTGGITTGCTACACCG & \\
\hline AVPR2 int $1 \mathrm{~F}$ & GTGGGCAGAGTGGGITTGAC & 151639 \\
\hline AVPR2 intl $R$ & CTCATTGGCAGCCTGGAGAG & \\
\hline HCFC ex17 F & TCTGATCACGGCACCTAGTGG & 151689 \\
\hline HCFC ex17 R & TCGGCGATGGTAACTGTGG & \\
\hline IRAKI int9 $\mathrm{F}$ & CAGCCAGTAATTGCTTCACTGC & 151749 \\
\hline IRAK1 int9 $\mathrm{R}$ & CTGAATCCTGACGGAGACCC & \\
\hline Rett ex4 Fl & AGACGGTCAGCATCGAGGTC & 151764 \\
\hline Rett ex4 R1 & ССTTCCCGСTCTTCTCACC & \\
\hline Rett $€$ & AACTGGGAGAGGG & 151765 \\
\hline Rett e & TGCCAGTTCCTGGAGCTTTG & \\
\hline Rett e & ATGTATGATGACCCCACCCTG & 151766 \\
\hline Rett ex3 R & AGCGGCCAGATTTCCTTTG & \\
\hline$X Q 3273 \mathrm{~F}$ & TTGGCCACTGAGAAACCCTC & 151848 \\
\hline XQ3273 R & CGGAGAGCAGGACCAGGTAG & \\
\hline TKTL ex12 F & GAATTCCCTTCGCTGTTIGC & 152027 \\
\hline TKTL ex12 R & GGAGGCTCTCATCACAAGCAG & \\
\hline FLNA 3'F & TCAGCTTTCTCGCCACATCC & 152044 \\
\hline FLNA 3'R & TCAGAAGGTCTGGGTITGACG & \\
\hline FLNA int29 F & ACAGGCATGGAGGGTCACC & 152053 \\
\hline FLNA int $29 \mathrm{R}$ & TGCCGCAAAACTCTAGCCAC & \\
\hline FLNA & CAG & 52055 \\
\hline FLNA i & & \\
\hline FLNA ex21 F & GCTCGAGTGCTTGGACAATG & 152057 \\
\hline FLNA ex21 R & GGGTGTCAGCGAAGAGGATG & \\
\hline FLNA exInt18 F & CTGTCCAGCAGGTAGCCACAC & 152058 \\
\hline FLNA exInt18 R & AGAAAGTCCCTCGGAGCTGTC & \\
\hline FLNA intl $4 \mathrm{~F}$ & TCAAGTGGTTGTGGCACACC & 152060 \\
\hline FLNA intl $4 \mathrm{R}$ & GCAAAGCCACAGCAGAAAGC & \\
\hline FLNA int8 F2 & CTCACGCTITCACCTTCGG & 152062 \\
\hline FLNA int8 R2 & AGTACCGTTGACCCTGTGGG & \\
\hline FLNA intl $\mathrm{F}$ & TGGTTGGTAG & 15206 \\
\hline FLNA intl $\mathrm{R}$ & GAGAACGAA & \\
\hline EMD 3'UTR F & CATGCACGCTACCAGCAGTC & 152078 \\
\hline EMD 3'UTR R & AGAATGATGTGCCAGAGACGC & \\
\hline \multicolumn{3}{|l|}{ Reference amplicons } \\
\hline PMP22 ex3 F & GCCACCATGATCCTGTCGAT & $17 \mathrm{p} 11.2$ \\
\hline PMP22 ex3 R & CCCTTGGTGAGGGTGAAGAGT & \\
\hline ALB ex12F & AATGCTGCACAGAATCCTTGGT & $4 q 11-q 13$ \\
\hline ALB ex12 R & TCATCGACTTCCAGAGCTGAAA & \\
\hline
\end{tabular}


amplicons in LICAM, LCA10, and AVPR2, plus FLNA amplicons int25, ex21, exInt18, and int14 were run with four female and two male controls. All other amplicons were run with two female and one male control). Calculation of standard deviations for normalised values (as for assays using the TaqMan technology) is not possible for SYBR green detection because of the independent amplifications of target and control. Normalised values of 1.0 indicate a diploid (female) situation, values of 0.5 or 1.5 indicate partial haploidy or partial triploidy respectively.

\section{Cytogenetic analysis}

Cytogenetic analysis on cultured blood lymphocytes had been performed earlier. GTG and QFQ banded metaphases at a resolution of 550-600 bands revealed no numerical or structural aberration (not shown).

Fluorescence in situ hybridisation (FISH) analyses were carried out on metaphase spreads using a probe generated from cosmid LLNLcl10C1837Q (GenBank accession no. AF031077), containing a total of $12 \mathrm{~kb}$ of genomic sequence from the large second intron of MECP2. The cosmid clone was obtained from the Resource Center of the German Human Genome Project (RZPD, Berlin, Germany). After culturing and DNA preparation, cosmid DNA was briefly sonicated and labelled directly with dGreen using the ULS universal linkage system (Q-Biogene) according to the instructions of the manufacturer. Dual colour FISH was performed with the cosmid probe, and with a probe mix generated from PCR amplified fragments of the FLNA gene (four PCR fragments containing a total of $5.5 \mathrm{~kb}$ between FLNA introns 18 and 29) labelled directly with rhodamine. Hybridisations were carried out for $12-18 \mathrm{~h}$ at $37^{\circ} \mathrm{C}$ following a standard protocol. ${ }^{18}$ Slides were evaluated using an Axioscope 2 Plus microscope (Zeiss, Germany) and the Isis software (Metasystems, Germany).

\section{X chromosome inactivation}

$\mathrm{X}$ chromosome inactivation was analysed by PCR amplification in the androgen receptor gene $(A R)$ as described. ${ }^{19}$ Genomic DNA of the probands was digested with either $M s p \mathrm{I}$ or methylation sensitive HpaII, or incubated with restriction buffer only. A 280 bp fragment of $A R$ exon 1 was then amplified incorporating ${ }^{32} \mathrm{P}$ labelled dCTP, separated on denaturing polyacrylamide gels, and evaluated using a Storm860 phosphoimager (Molecular Dynamics, CA, USA). The ratio of inactivation of the alleles in informative females was calculated from the band intensities measured by the ImageQuant 5.1 software (Molecular Dynamics).

\section{Test of integrity of FLNA}

The restriction map of $F L N A^{20}$ shows a central $21.2 \mathrm{~kb} E c o$ RI fragment (EcoRI sites in intron 1 and exon 41 of FLNA). To test for integrity of one functional gene copy of FLNA, $10 \mu \mathrm{g}$ of genomic DNA of the index patient were digested with EcoRI, and a Southern blot performed. The blot was hybridised with a ${ }^{32} \mathrm{P}$ labelled probe generated from a PCR fragment made with FLNA primers int8F and intl4R (outside the duplicated region), and evaluated by autoradiography.

\section{MECP2 expression analysis}

Total RNA of the patient, his mother, and male and female controls was extracted from lymphoblastoid cells generated by EBV transformation. Expression of MECP2 was analysed by one step RT real time PCR with SYBR Green detection and the comparative threshold cycle method. Primers Rett $2 \mathrm{~F}$ and Rett 3-2R were used to amplify a 277 bp MECP2 mRNA fragment. Quantification was performed against a control amplicon of the GAPDH mRNA, using primers GAPDH-F (AGGTCGGAGTCAACGGATTTG) and GAPDH-R (AAGCAG CCCTGGTGACCAG). Reactions for MECP2 and GAPDH were carried out three times in duplicate using the Quantitect SYBR Green RT-PCR kit (Qiagen, Germany). Reaction tubes contained $0.4 \mu \mathrm{mol} / \mathrm{l}$ each primer of a pair, $10 \mu \mathrm{l}$ QuantiTect SYBR Green, $0.2 \mu \mathrm{l}$ QuantiTect RT mix, and $20 \mathrm{ng}$ RNA (total volume $20 \mu \mathrm{l})$. Fluorescein $(0.2 \mu \mathrm{l}$ diluted $1: 1000)$ was added for internal calibration of the iCycler system. Cycling conditions were $50^{\circ} \mathrm{C}$ for 30 minutes, $95^{\circ} \mathrm{C}$ for 15 minutes, and 40 cycles of $94^{\circ} \mathrm{C}$ for 15 seconds, then $60^{\circ} \mathrm{C}$ for 30 seconds, and $72^{\circ} \mathrm{C}$ for 30 seconds (data collection step), followed by a melting curve analysis. Quantification of relative $M E C P 2$ expression was performed as described for relative gene dosage calculation (see above).

\section{RESULTS}

The analysis of MECP2 gene dosage was performed repeatedly by independent comparison of three amplicons in $M E C P 2$ to autosomal reference amplicons, and suggested existence of two gene copies in the index patient, identical to the gene dosage found in girls. Chromosome analysis by conventional cytogenetics had earlier revealed a normal karyotype 46,XY in the boy (not shown). To verify a MECP2 duplication, additional amplicons $5^{\prime}$ and $3^{\prime}$ of the gene, situated in IRAKI intron 9 and in STS XQ3273 (GenBank accession no. G66748) were analysed. Double dosage was found for both amplicons, indicating a complete duplication of MECP2 (fig 1). No such findings were found in a cohort of 75 female and 17 male patients suspected with Rett syndrome who had tested negative for smaller intragenic mutations.

EDTA blood samples had been received after informed consent for dosage analysis in the family of the index patient (fig 2A). An increased dosage for all MECP2 amplicons was found for the patient himself (III.2) and his mother (II.2), indicating two gene copies in the index patient and three copies in his healthy mother. Normal MECP2 dosage was detected in the healthy brother (III.1), father (II.1), and maternal uncle (II.3) (fig 2B).

The extent of the duplication was determined by application of further amplicons in Xq27-q28, situated in $\mathrm{HCFCl}$, AVPR2, LICAM, and FMR1 (centromeric to MECP2) and TKTL1, FLNA, EMD, G6PD, and F8 (telomeric to MECP2). The evaluation showed that the duplication involves a region including AVPR2 to TKTL1, but not the amplicons situated in LICAM and in FLNA intronl (fig 1). Dosage of the more distant genes FMRI, EMD, G6PD, and F8 was also normal (not shown).

An amplicon in the first intron of LCA10 (GenBank accession no. AF5 14420), a predicted gene encoding for lung carcinoma associated protein, was analysed to determine possible involvement of LICAM. Single dosage for the LCA1O amplicon was found repeatedly in the assay. This suggests localisation of the proximal breakpoint to a $21 \mathrm{~kb}$ region between $L C A 10$ intron 1 and AVPR2 intron 1, at least $8.4 \mathrm{~kb} 5^{\prime}$ of the first exon of LICAM. No regulatory sequences of LICAM are known further upstream, thus practically excluding LICAM contribution to the phenotype of this patient (fig. 1).

Further amplicons in the FLNA gene were applied for fine mapping of the distal breakpoint between TKTL1 exon 12 and FLNA intron 1. The distal breakpoint was finally located to an approximately $2 \mathrm{~kb}$ segment between an amplicon in FLNA intron 14 and an amplicon at the border of exon 18 to intron 18 of FLNA (fig 1). The aberration thus includes complete duplication of 12 genes and predicted transcripts (AVPR2, ARHGAP4, ARD1, RENBP, HCFC1, IRAK1, MECP2, OPNILW, OPNIMW, TKTL1, CXorf12, and CXorf2), plus partial duplication of FLNA (and possibly of predicted transcript LCA1O).

The mother of the index patient was informative for the trinucleotide repeat polymorphism at the $A R$ site. The analysis demonstrates severely skewed $\mathrm{X}$ inactivation in the mother. Quantification of the X inactivation of the two alleles 

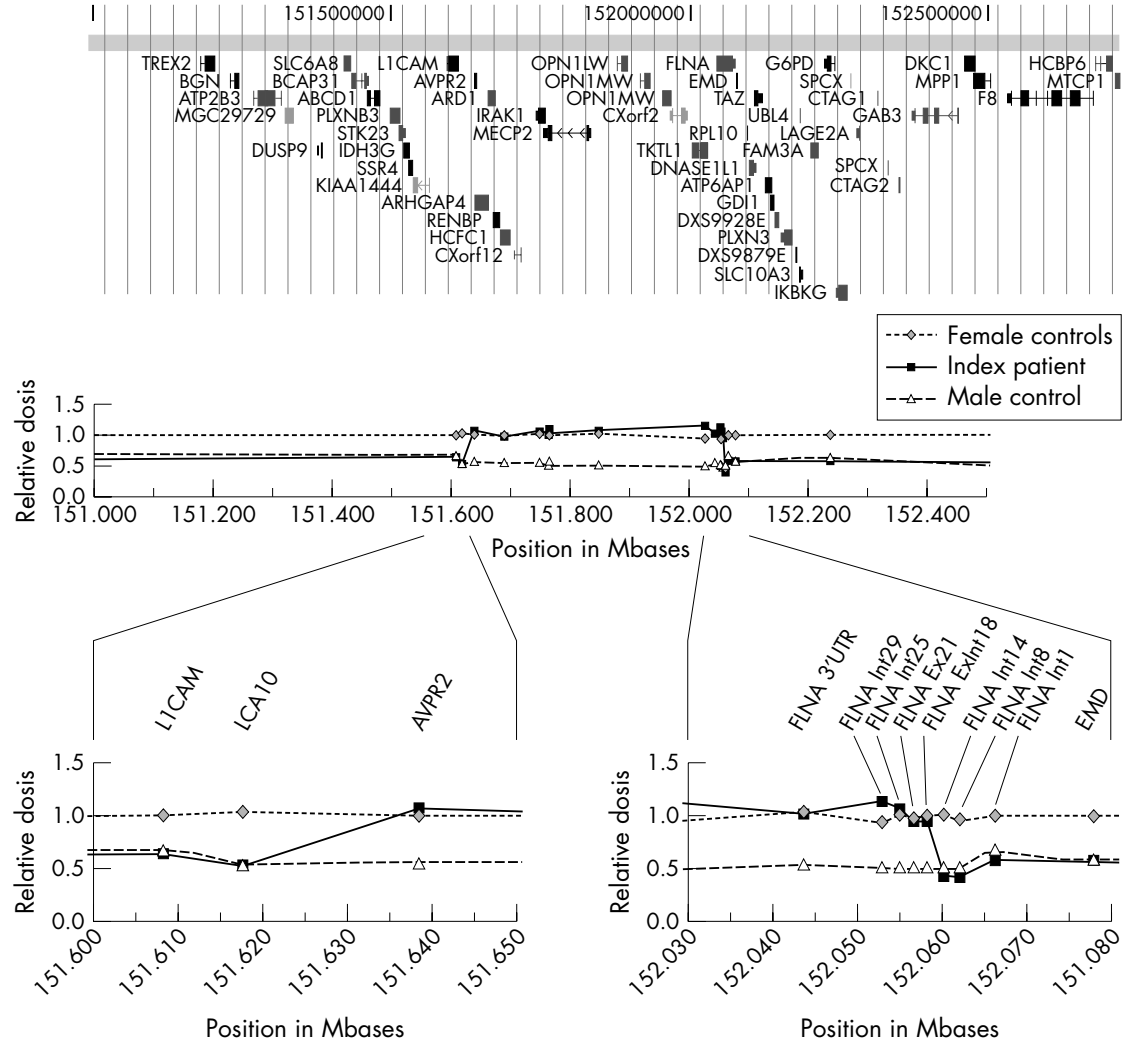

indicated a ratio of more than 10:1 for the patient's mother, whereas a ratio of 7:3 and 6:4 was found for the two informative female controls c2 and c3 (fig 2C). The index patient, his brother, and his maternal uncle all carry the same, active allele at the $A R$ locus. This is also the allele preferentially unmethylated in the mother, indicating recombination between the $A R$ gene at Xq11 and MECP2 at $\mathrm{Xq} 28$ in the index patient (fig 2C).

FISH analysis with a probe for $M E C P 2$, generated from cosmid LLNLC110C1837Q, showed only one signal in the telomeric region of Xq in all analysed metaphases (fig 3). This suggested an intrachromosomal duplication with integration next to the originating segment. Dual colour FISH was applied with the same probe and a probe mix from the duplicated region of FLNA. In one metaphase, a pattern of fluorescent signals compatible with an orientation cenFLNA (partial)-MECP2-MECP2-FLNA-tel was observed. This result, however, which suggests an inverted tandem duplication with integration into the distal breakpoint, could not be verified in other metaphases, probably due to a limited resolution of this $\sim 430 \mathrm{~kb}$ duplication in the FISH analysis.

Southern blot analysis with a probe outside the duplicated region revealed the expected $21 \mathrm{~kb}$ central EcoRI fragment of FLNA in the index patient, his mother, and controls, confirming integrity of FLNA (data not shown).

Expression of $M E C P 2$ was analysed at the mRNA level in lymphoblastoid cells. No significant difference was found between male and female samples, as expected for a gene underlying $X$ inactivation in females. In contrast, quantification of transcript levels in the index patient suggests a double dose of MECP2 transcription (fig 2D). The patient's healthy mother had normal values.

\section{DISCUSSION}

$\mathrm{Xq} 28$ is a chromosomal region frequently affected by rearrangements, and contains several genes mutated in exact mutation involved. ${ }^{27}$
Figure 1 Characterisation of the duplication by dosage analysis for amplicons in Xq28 for the index patient, and female and male controls. Data points refer to amplicons amplified with primer pairs in table 1. Gene dosage was calculated relative to autosomal reference amplicons. Graphical representation of genes on $\mathrm{Xq} 28$ is adapted from the UCSC genome browser. $A B C D 1, L 1 C A M, M E C P 2, F L N A$, and EMD. ${ }^{21-25}$ The gene product of $M E C P 2$, the gene mutated in Rett syndrome, is involved in regulation of transcription by interaction with methylated DNA. In vitro, MECP2 has been found to act as a transcriptional repressor, although the target genes of MECP2 have yet to be identified. The precise effect of $M E C P 2$ mutations is only partly understood. It was previously speculated that MECP2 mutations would be lethal in boys, although it is now thought that the much higher incidence of Rett syndrome in girls is mainly caused by an overwhelming ratio of mutations on paternally derived $X$ chromosomes. ${ }^{26}$ Nevertheless, relatively few reports of Rett syndrome in males exist. The classic Rett phenotype has been described in males with Klinefelter syndrome or with somatic mosaicism, ${ }^{6-10}$ while in most other cases, MECP2 mutations in boys have been associated with a more severe clinical course culminating in neonatal encephalopathy. ${ }^{511}$ In contrast, there have been numerous reports on point mutations, small intragenic deletions, and larger deletions in MECP2 in girls, and a possible genotype-phenotype correlation has been studied in detail. Some authors have suggested that partial deletions and truncating mutations may be associated with a more severe phenotype. Other investigators have not observed this correlation, leading to the suggestion that Rett syndrome may be caused by loss of MECP2 function regardless of the

We report here a familial duplication of a submicroscopic Xq28 segment in a boy with severe mental retardation and features of Rett syndrome. Psychomotor development was primarily retarded. Regression and loss of purposeful hand use and other acquired abilities, stereotypic movements, autistic features, epileptic seizures, and feeding problems occurring between the ages of $4 \frac{1}{2}$ and $6 \frac{3}{4}$ years led to suspicion of Rett syndrome. Quantitative PCR revealed a duplication involving $M E C P 2$. As there are at least 12 genes 


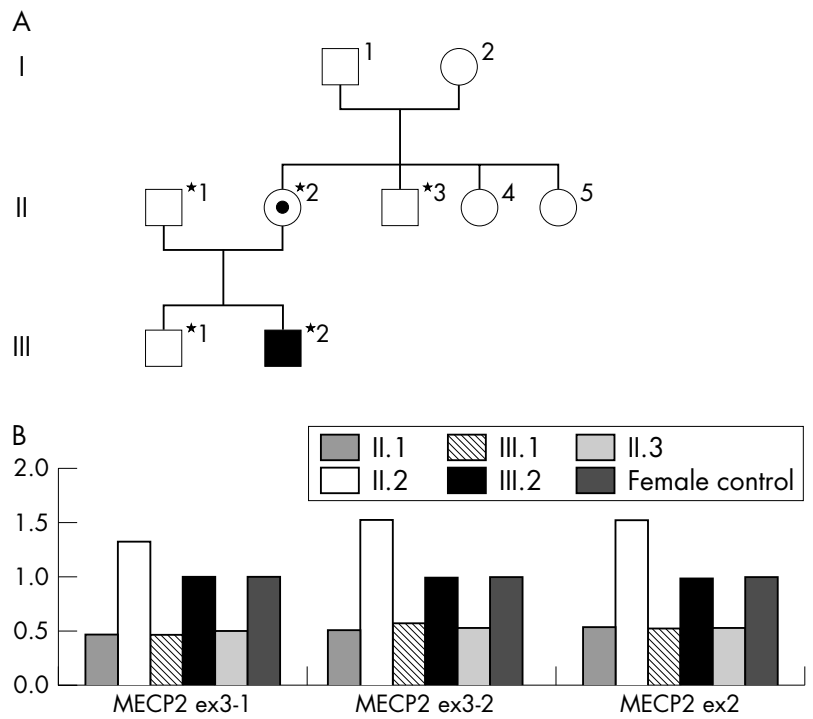

C
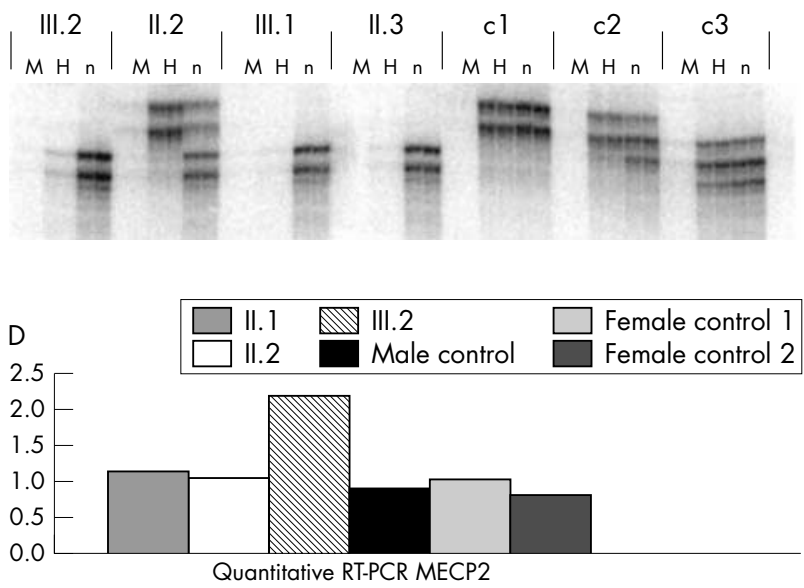

Figure 2 (A) Family tree of the index patient (III.2). *Subjects available for molecular genetic analysis. (B) Dosage analysis of three amplicons in MECP2 for the index patient (III.2), his parents (II. 1 and II.2), his maternal uncle (II.3), and female controls. (C) X inactivation analysis at the AR locus. Methylation status at the polymorphic site in AR exon 1 was studied by PCR either after digest with Mspl $(M)$, Hpall $(H)$, or no digest (n). (D) Results of quantitative RT PCR in lymphoblasts of the patient, his mother, and male and female controls.

and predicted transcripts included in the duplication, we cannot rule out that other genes may contribute to the clinical phenotype, although none of these genes other than MECP2 (and the colour opsin genes) is known to play a fundamental role in neural development and maintenance. There is convincing experimental evidence that complete, functional gene copies exist for both LICAM and FLNA, the two nearest genes responsible for well known neurological phenotypes. Although LICAM is not included in the duplication, fine mapping of the distal breakpoint indicated partial duplication of FLNA. Protein synthesis from the partially duplicated gene copy lacking the promoter and at least exons $1-13$ is most unlikely, especially as periventricular heterotopia was excluded by MRI. In combination with the clinical phenotype, the results indicate that duplication of $M E C P 2$ may be the major if not the only cause for the mental retardation syndrome in our patient. Even though primary psychomotor retardation and normal head growth are

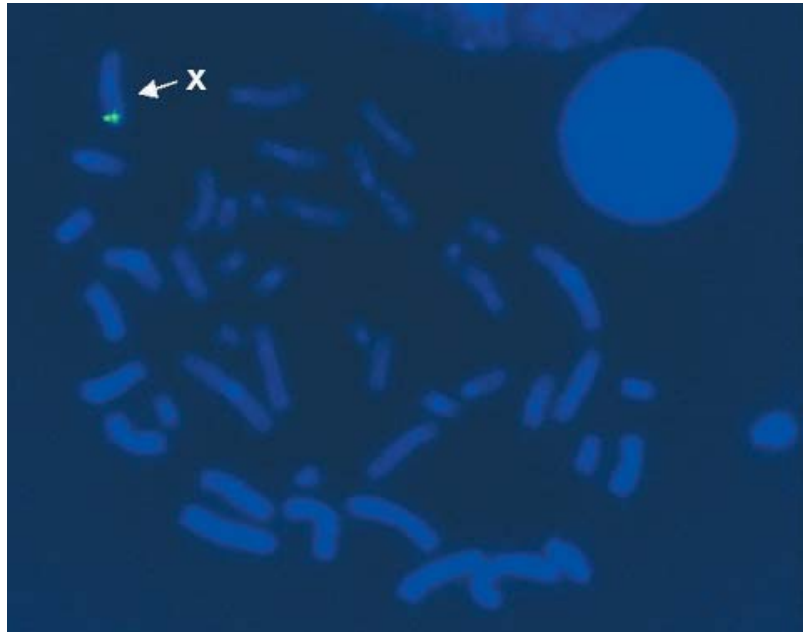

Figure $3 \mathrm{FISH}$ analysis in the index patient with an MECP2 probe (green) generated from cosmid LLNLC1 10C1837Q. The signal in the telomeric region of $\mathrm{Xq}$ could not be further resolved, suggesting an intrachromosomal duplication with integration next to the originating segment.

atypical findings, the patient shows many diagnostic signs of Rett syndrome.

Owing to the uninformative family history, it remains unclear whether submicroscopic duplications involving $M E C P 2$ could cause Rett syndrome or other deleterious conditions in female patients. The finding of extremely skewed X inactivation in the index patient's healthy mother, who also carries the duplication, suggests this hypothesis. This is further supported by the finding of elevated MECP2 mRNA levels in lymphoblastoid cells of the index patient, but not in his mother, compared with male and female controls. Importantly, in Mecp 2 transgenic mice, the overexpression of murine Mecp 2 causes a neurological phenotype similar to that in Mecp 2 deficient mice. ${ }^{28}$

In conclusion, our results indicate that duplications of the MECP2 gene caused by intrachromosomal duplications of Xq28 are rare, but are sufficient to cause a clinical phenotype similar to Rett syndrome in boys and possibly girls. These findings may also have implications for development of potential gene therapy strategies for Rett syndrome. The case demonstrates that alteration of methylation patterns due to pure loss of MECP2 function is not the only mechanism involved in pathogenesis of Rett syndrome, but that elevated dosage of MECP2 may be more critical than previously thought.

\section{ACKNOWLEDGEMENTS}

We thank the parents for their cooperation. We also thank J Karimzad Hagh and D Falkenstein for expert technical assistance.

\section{Authors' affiliations}

M Meins, F Gerresheim, J Herchenbach, M Hagedorn, J T Epplen,

Department of Human Genetics, Ruhr-University Bochum, Germany J Lehmann, K Hameister, Fachklinik fuer Kinderneurologie und Sozialpaediatrie Königsborn, Unna, Germany

Competing interests: there are no competing interests

Correspondence to: Dr M Meins, Department of Human Genetics, RuhrUniversity Bochum, Universitaetsstrasse 150, 44801 Bochum, Germany; moritz.meins@ruhr-uni-bochum.de

Received 8 June 2004

Revised 12 August 2004

Accepted 16 August 2004 


\section{REFERENCES}

1 Zoghbi H. Genetic aspects of Rett syndrome. J Child Neurol 1988;3(suppl):S76-8.

2 Amir RE, Van den Veyver IB, Wan M, Tran CQ, Francke U, Zoghbi HY. Rett syndrome is caused by mutations in X-linked MECP2, encoding methyl-CpGbinding protein 2. Nat Genet 1999;23:185-8.

3 Hagberg B. Clinical manifestations and stages of Rett syndrome. Ment Retard Dev Disabil Res Rev 2002;8:61-5.

4 Huppke P, Held M, Laccone F, Hanefeld F. The spectrum of phenotypes in females with Rett Syndrome. Brain Dev 2003;25:346-51.

5 Schanen NC, Kurczynski TW, Brunelle D, Woodcock MM, Dure LS IV, Percy AK. Neonatal encephalopathy in two boys in families with recurrent Rett syndrome. J Child Neurol 1998;13:229-31.

6 Schwartzman JS, De Souza AM, Faiwichow G, Hercowitz LH. (Rett phenotype in patient with XXY karyotype: case report). Arq Neuropsiquiatr 1998;56:824-8

7 Salomao Schwartzman J, Zatz M, dos Reis Vasquez L, Ribeiro Gomes R, Koiffmann CP, Fridman C, Guimaraes Otto P. Rett syndrome in a boy with a 47, XXY karyotype. Am J Hum Genet 1999:64:1781-5.

8 Clayton-Smith J, Watson P, Ramsden S, Black GC. Somatic mutation in MECP2 as a non-fatal neurodevelopmental disorder in males. Lancet 2000;356:830-2.

9 Armstrong J, Pineda M, Aibar E, Gean E, Monros E. Classic Rett syndrome in a boy as a result of somatic mosaicism for a MECP2 mutation. Ann Neurol 2001;50:692.

10 Schwartzman JS, Bernardino A, Nishimura A, Gomes RR, Zatz M. Rett syndrome in a boy with a $47, X X Y$ karyotype confirmed by a rare mutation in the MECP2 gene. Neuropediatrics 2001;32:162-4.

11 Moog U, Smeets EE, van Roozendaal KE, Schoenmakers S, Herbergs J, Schoonbrood-Lenssen AM, Schrander-Stumpel CT. Neurodevelopmenta disorders in males related to the gene causing Rett syndrome in females (MECP2). Eur J Paediatr Neurol 2003;7:5-12.

12 Van den Veyver IB, Zoghbi HY. Genetic basis of Rett syndrome. Ment Retard Dev Disabil Res Rev 2002;8:82-6.

13 Laccone F, Junemann I, Whatley S, Morgan R, Butler R, Huppke P, Ravine D. Large deletions of the MECP2 gene detected by gene dosage analysis in patients with Rett syndrome. Hum Mutat 2004;23:234-44.

14 Mnatzakanian GN, Lohi H, Munteanu I, Alfred SE, Yamada T, MacLeod PJ, Jones JR, Scherer SW, Schanen NC, Friez MJ, Vincent JB, Minassian BA. A previously unidentified MECP2 open reading frame defines a new protein isoform relevant to Rett syndrome. Nat Genet 2004;36:339-41.

15 Wilke K, Duman B, Horst J. Diagnosis of haploidy and triploidy based on measurement of gene copy number by real-time PCR. Hum Mutat 2000;16:431-6.
16 Ponchel F, Toomes C, Bransfield K, Leong FT, Douglas SH, Field SL, Bell SM Combaret V, Puisieux A, Mighell AJ, Robinson PA, Inglehearn CF, Isaacs JD, Markham AF. Real-time PCR based on SYBR-Green I fluorescence: an alternative to the TaqMan assay for a relative quantification of gene rearrangements, gene amplifications and micro gene deletions. BMC Biotechnol 2003;3:18.

17 Karolchik D, Baertsch R, Diekhans M, Furey TS, Hinrichs A, Lu YT, Roskin KM, Schwartz M, Sugnet CW, Thomas DJ, Weber RJ, Haussler D, Kent WJ, University of California Santa Cruz. The UCSC Genome Browser Database. Nucleic Acids Res 2003;31:51-4.

18 Rooney DE. Human cytogenetics: a practical approach, 3rd ed. Oxford: Oxford University Press, 2001.

19 Allen RC, Zoghbi HY, Moseley AB, Rosenblatt HM, Belmont JW. Methylation of Hpall and Hhal sites near the polymorphic CAG repeat in the human androgen-receptor gene correlates with X chromosome inactivation. Am J Hum Genet 1992;51:1229-39.

20 Small K, lber J, Warren ST. Emerin deletion reveals a common X-chromosome inversion mediated by inverted repeats. Nat Genet 1997;16:96-9.

21 Laporte J, Hu U, Kretz C, Mandel JL, Kioschis P, Coy JF, Klauck SM, Poustka A, Dahl N. A gene mutated in X-linked myotubular myopathy defines a new putative tyrosine phosphatase family conserved in yeast. Nat Genet 1996;13:175-82.

22 Mosser J, Douar AM, Sarde CO, Kioschis P, Feil R, Moser H, Poustka AM, Mandel JL, Aubourg P. Putative X-linked adrenoleukodystrophy gene shares unexpected homology with $A B C$ transporters. Nature 1993:361:726-30.

23 Rosenthal A, Jouet $M$, Kenwrick S. Aberrant splicing of neural cell adhesion molecule L1 mRNA in a family with X-linked hydrocephalus. Nat Genet 1992;2:107-12.

24 Fox JW, Lamperti ED, Eksioglu YZ, Hong SE, Feng Y, Graham DA, Scheffer IE, Dobyns WB, Hirsch BA, Radtke RA, Berkovic SF, Huttenlocher PR, Walsh CA. Mutations in filamin 1 prevent migration of cerebral cortical neurons in human periventricular heterotopia. Neuron 1998;21:1315-25.

25 Bione S, Maestrini E, Rivella S, Mancini M, Regis S, Romeo G, Toniolo D. Identification of a novel $X$-linked gene responsible for Emery-Dreifuss muscular dystrophy. Nat Genet 1994;8:323-7.

26 Trappe R, Laccone F, Cobilanschi J, Meins M, Huppke P, Hanefeld F, Engel W. MECP2 mutations in sporadic cases of Rett syndrome are almost exclusively of paternal origin. Am J Hum Genet 2001;68:1093-101.

27 Kriaucionis S, Bird A. DNA methylation and Rett syndrome. Hum Mol Genet 2003; 12(suppl 2):R221-7.

28 Luikenhuis S, Giacometti E, Beard CF, Jaenisch R. Expression of MeCP2 in postmitotic neurons rescues Rett syndrome in mice. Proc Natl Acad Sci USA 2004;101:6033-8. 